\title{
Navigating care for Bedouin patients with diabetes
}

\author{
Shauna Dunton, Alison Higgins, Jonathan Amkraut, Yones Abu-Rabia
}

Medical School for International Health, Ben Gurion University, Beer Sheva, Israel

\section{Correspondence to} Jonathan Amkraut, Jonathan.amkraut@gmail.com

$\mathrm{SD}, \mathrm{AH}$ and $\mathrm{JA}$ are equal contributors.

Accepted 22 February 2016 BMJ Case Rep Published online: [please include Day Month Year] doi:10.1136/ bcr-2015-214022

\section{SUMMARY}

The Bedouin Arab population in the southern Negev region of Israel has faced health problems as a result of transitioning rapidly from a nomadic agricultural lifestyle to a more modern urban lifestyle. Like many populations around the world, the Bedouins have changed their diets and become more sedentary and this has led to a high rate of diabetes. In this case report, we examine how diabetes has affected the life of an influential man in the Bedouin community and the significance this case has in the greater context of a global rise in chronic disease.

\section{CASE PRESENTATION \\ Patient background}

The patient is an approximately 60-year-old Bedouin man with diabetes who lives in a Bedouin city in the Israeli Negev desert region. He lives with his family and holds the position of sheik within his tribe. This position has been passed down in his family from father to son for generations. As sheik, his responsibilities include hosting people from the community who come for advice and attending community ceremonies such as weddings. Traditionally, the sheik and his family also offer hospitality to guests visiting from out of town. All of these traditions involve the serving and consumption of sweet drinks and high carbohydrate foods such as sweet tea, spiced coffee, rice, laffa bread, fruit and cookies. Additionally, a more modern custom is to bring soft drinks as a gift on a visit. These cultural norms present a challenge to diabetes care and management.

The patient grew up in a small village lacking infrastructure such as electricity and water services and his family lived in a tent. He did manual labour such as farm work and walked a long distance to school each day. Now his family lives in a permanent home and has a car and other modern technologies, all of which have resulted in a more sedentary lifestyle. The patient has three wives, which is consistent with Bedouin tradition but difficult from a legal standpoint in Israel. While it is formally illegal, it is tolerated by the authorities. Since moving to the recognised Bedouin city, his family has had more medical problems. His parents and siblings all have type II diabetes and one of his sisters died from resulting complications.

\section{Patient's medical history}

The patient was diagnosed with type II diabetes almost 30 years ago. A local doctor and fellow Bedouin made the diagnosis after the patient registered a high-blood glucose level. However, despite the doctor's understanding of Bedouin culture, encouraging the patient to make lifestyle changes after the diagnosis proved virtually impossible. The patient needed to stop eating foods containing high sugar and carbohydrate levels and to start exercising more regularly. However, the patient felt fine and thus did not want to follow his prescribed treatment. The patient took his prescriptions of insulin and metformin, but did not make lifestyle changes. As a result of complications from his diabetes, he suffered kidney failure in 2012 and required three $4 \mathrm{~h}$ dialysis sessions per week. This continued while he waited to receive a kidney transplant.

Despite physician warnings and his sister's early death from diabetes complications, the patient only adjusted his diet and lifestyle after his kidney failed. By his own report, the patient was reluctant to make the necessary changes due to arrogance and a belief that he was unable to change his fate. More recently, the patient served as an advocate to try to encourage other Bedouins to make lifestyle changes so they do not suffer the same outcome.

During our work on this paper, the patient unexpectedly passed away. It is unclear exactly what happened as the patient was on a trip with family. His doctor informed us that the patient most likely died from a heart attack due to complications from chronic diabetes.

\section{GLOBAL HEALTH PROBLEM LIST}

1. Global rise in chronic disease, especially for populations undergoing modernisation and urbanisation

2. Low socioeconomic status as a factor in the prevalence of chronic disease

3. Tension between belief in fatalism and adherence to medical treatment plans

4. Necessity of culturally competent healthcare providers

5. Adjusting attitudes towards traditional usage of medical services to include prevention

6. Overcoming the stigmatisation of chronic disease.

\section{GLOBAL HEALTH PROBLEM ANALYSIS}

\section{Global rise in chronic disease}

The trend of increasing risk and incidence of diabetes and other serious chronic diseases has been documented around the world. This pattern has been observed in populations rapidly transitioning from an agricultural to an urban environment such as Guatemalans and Indians, and in populations undergoing urbanisation as part of a minority culture within a larger Western society such as African-American women, Hispanic American youth and Native Americans. ${ }^{1-5}$ In addition, many 
developing countries which have successfully controlled infectious diseases such as tuberculosis and malaria are now seeing chronic disease as a more pressing threat. The WHO reports that chronic diseases such as heart disease, stroke, cancer, chronic respiratory diseases and diabetes lead to $60 \%$ of total deaths worldwide. This makes chronic disease the leading cause of worldwide mortality. ${ }^{6}$

\section{Urbanisation and modernisation of the Bedouin people}

The Bedouin population is yet another population experiencing an increase in prevalence of chronic disease in the context of modernisation and urbanisation. ${ }^{7}$ The term Bedouin refers to a group of historically nomadic Arab tribes in the Middle East. Bedouins lived as herders and agriculturists for generations. ${ }^{9} \mathrm{Up}$ until the early 20th century, the Bedouins in the Negev region were dispersed throughout Saudi Arabia, Egypt and what was then the southern deserts of Palestine. Each tribe controlled their own territory where their livestock grazed with some territories spanning up to thousands of miles. ${ }^{10}$ The Bedouins formerly lived in tents, often carrying wood and water used for heating and cooking. They also walked long distances and did agricultural work which kept them in good physical shape. ${ }^{9}$ In 1968, with the planned settlement of Tel Sheva, the Israeli government began with their relocation of the Bedouin people to designated areas. ${ }^{11}$ The new homes in the settled areas have less room to raise livestock or grow crops. ${ }^{9}$ The lifestyle changes, such as frequent usage of cars, and also household appliances that decrease the need for physical work have also led to a more sedentary lifestyle. ${ }^{12}$ The rapid urbanisation experienced by those who moved has had significant effects on health. Bedouins have experienced an increase in obesity and related morbidity rates due to drastic changes in traditional means of livelihood and diet. ${ }^{12}$

Bedouin communities have resisted relocation to planned towns for fear of cultural loss and loss of traditional resources. ${ }^{11}$ Instead, many have chosen to remain in what are referred to as 'unrecognised villages'. Unrecognised villages are populated areas that lack formal municipalities and contain makeshift homes mostly constructed from corrugated tin. In these unrecognised towns, Bedouins are able to live a slightly more traditional life. The Israeli government has attempted to create more appealing housing options for the Bedouins that keep some aspects of traditional life in order to influence them to move and many have now accepted these government-planned towns. ${ }^{11}$

\section{Chronic disease among Bedouin patients}

The move of the Bedouins to permanent cities with a subsequent decrease in physical activity and an increase in caloric consumption has affected the experience of residents predisposed to chronic disease. Diabetes and cardiovascular disease are multifactorial diseases in which genetics and heredity play a role, in addition to diet and lifestyle. ${ }^{13}{ }^{14}$ Major factors such as easier access to unhealthy foods and beverages and loss of a traditional lifestyle which involved more physical activity are thought to have contributed to the recent rise in cardiovascular disease and incidence of diabetes in the Bedouin population. ${ }^{8} 9$ New technologies have helped to increase access to information about health, chronic disease, and options for prevention and treatment both in Bedouin society and the larger Israeli society.

However, the gap in access to information and resources, as well as in rates of chronic disease between Jewish-Israeli and Bedouin-Israeli patients, remains large. ${ }^{9}$ Analogously, this disparity in access to health information is also seen in the USA between whites and Hispanics as measured by differences in access to computers and the internet between these populations. ${ }^{15}$

Even though the Bedouins are now living within a developed nation, they have greater rates of poverty and poorer health than the general population of Israel. Both poor health and low socioeconomic status have been linked to a rise in chronic disease. In $2007,66 \%$ of Bedouins in the Negev region were reportedly living below the poverty line. ${ }^{16}$ As of $2010,35 \%$ of Bedouins were considered unemployed and this population had the lowest employment rate in Israeli society. ${ }^{17}$ Low socioeconomic status has been linked to diabetes and diabetes-related complications. ${ }^{18}$ A study in 2008 reported that the obesity rate in the Bedouin population was $28 \%$ as compared to $20 \%$ in the Jewish population, which is in sharp contrast to findings in 1964 reporting that obesity was a rarity among Bedouin populations. ${ }^{12}$

\section{Fatalism}

Another significant element in our patient's story is the idea of fatalism. Fatalism is largely a religious teaching that says God has a predetermined plan, including a predetermined day of death for every individual. Owing to this strong faith that God has 'written' what will happen, hoping to change this with your behaviour is at best foolish and at worst offensive and arrogant. A doctor at the Rahat diabetes clinic found this to be one of the most common reasons for a lack of interest in changing health behaviours. Fatalism plays a key role in many communities facing a high risk for lifestyle-related deadly diseases. ${ }^{19}$ For example, Heerman and Wills ${ }^{20}$ found that many refugees in the USA were unable to adhere to long-term treatment regimens due to fatalistic beliefs. The effect of fatalism on health varies, but generally prevents patients from believing in the effectiveness of modifying long-standing behaviours that might lead to better health. This idea leads patients to feel hopeless and powerless and to poor disease management. ${ }^{21}$ In a study investigating fatalism and glycaemic control in the context of diabetes management, Walker $e t a{ }^{21}$ found that fatalism is linked to low levels of adherence to treatments. They concluded that interventions focused on addressing this fatalistic attitude may be beneficial for diabetes care. Our patient and his doctor both cite fatalism as a main obstacle in educating and motivating Bedouin patients. To address the challenge of fatalistic attitudes, our patient's doctor talks to patients about quality of life rather than the threat of death. He has patients consider how changes in lifestyle will help in remaining strong and active until the prewritten day of death.

Trust between minority communities and healthcare systems

The fact that our patient's doctor is a Bedouin allows him to better connect with and treat his patients. The doctor's knowledge of the relevant cultural norms and traditions leads to more patient trust and this high level of trust is key in getting patients to take his medical advice. Making dietary adjustments, selfadministering daily shots and travelling long distances to clinics can be major and unfamiliar lifestyle changes, but patient trust in the doctor can help to ease adaptation to these changes.

The link between trust and the adherence to treatment regimens is found within many minority communities. For example, African-Americans in US cities have a history of power imbalances that have resulted from being a minority community within a larger majority. This dynamic can lead to poor health outcomes. Studies have shown that African-Americans who held high levels of cultural mistrust towards the majority-run clinics also held low scores of dietary adherence. ${ }^{3}$

The Zuni Indian community in the USA is another group that is a minority within a larger Western Culture. This group has 
experienced negative health effects as a result of rapid, forced modernisation. Their major health problems include obesity, diabetes, hypertension and kidney disease. ${ }^{5}{ }^{22}$ Lack of medical treatment and adherence to treatment for these conditions has been attributed to many factors including unfamiliarity in navigating the medical system, problems relating to healthcare professionals, and long travel distances to clinics. ${ }^{22}$ Awareness of available resources and embarrassment from stigma were also identified as barriers to healthcare in the Zuni minority community, reinforcing the importance of addressing these obstacles. ${ }^{22}$ These obstacles may not be immediately apparent to healthcare providers, underscoring the importance of culturally appropriate intervention channels.

\section{Stigma}

Another factor contributing to the rise in diabetes is the stigma that comes with the disease diagnosis. The severe effect of disease stigma is reflected around the world with diabetes, as well as with mental illnesses, leprosy, tuberculosis and AIDS, where those who are affected are often discriminated against. ${ }^{23}{ }^{24}$ For example, discrimination against patients with AIDS has manifested in ways such as banning of entry to certain places of infected individuals and husbands leaving pregnant wives on learning of a positive HIV status. ${ }^{24}$ In the Zuni Native American community in the USA, Newman et al observed a pattern of afflicted individuals lacking knowledge about diabetes progression and management and citing stigma as a barrier to diabetes self-management. Stigma can limit the sharing of information between individuals regarding disease management and also limit community support for healthy choices. ${ }^{5}$ For this reason, changing family and cultural attitudes towards treatment and prevention efforts has been shown to be instrumental in improving adherence to treatment.

When our patient was diagnosed, the Bedouin community had little familiarity with diabetes, overall. This made making lifestyle changes even more difficult because the community was less likely to be understanding if an individual needed to refuse hospitality in the form of food or drink. The diagnosis could also hurt a patient's social status. ${ }^{7}$ In many societies, admitting to having an abnormal condition can reduce marriage prospects for an individual and even for the family of the individual. ${ }^{25} \mathrm{In}$ the case of diabetes, where there is a lack of easily recognisable symptoms, disclosing the disease can feel like a greater risk than the possible medical complications of the disease. ${ }^{26}$ Our patient did not feel like this was a main reason he had difficulty with the disease. His perceived lack of vulnerability to stigma may be a result of his high status. He also believed that since diabetes has become so much more common in Bedouin society, stigma is becoming less of a contributing factor to poor diabetes management.

\section{Bedouin usage of and access to healthcare services}

Another contributing factor to the diabetes problem among the Bedouins is that, even where there is access to free and highquality services, the Bedouin population generally uses health services differently than do individuals in Western society. Bedouins seek treatment for acute illness with tangible signs and symptoms, but do not see medical care as something preventative or useful for maintenance of a chronic medical condition. ${ }^{9}$ The use of medical advice and frequent check-ups to prevent these diseases are not as common among the Bedouins as they are in other populations in Israel. As a result, at-risk individuals are identified later during the development of warning signs and disease prognosis becomes worse.
Despite the fact that, for the most part, Bedouins traditionally seek medical services only in times of immediate need, there are also other reasons Bedouins fail to seek proper care. For example, sometimes it is difficult to get from an unrecognised Bedouin village to the nearest clinic. ${ }^{27}$ Without a private car or public transportation, getting to a clinic could mean a full day endeavour for a patient. Since many Bedouins are afflicted by poverty, the prospect of losing a day's work can cause them to avoid the doctor.

Our patient was somewhat insulated from these phenomena as he received more regular care due to his position in his society. He also had a private car and lived close to the clinic. However, even with his increased access to medical services and close proximity to the clinic, our patient still suffered kidney failure.

\section{The role of leaders}

When prompted to pose solutions for the diabetes problem facing the Bedouins, our patient suggested that community members need to lead changes in the local community. Teachers at the local schools must educate the community about the dangers of diabetes. Our patient also followed his own advice, using his position in Bedouin society as a means to engage the community about diabetes education. Another possible platform for diabetes education in the Bedouin community could be wellbaby clinics. In the Bedouin city of Rahat, these clinics are taken very seriously by mothers. These clinics offer free information, free vaccinations and formula to new parents. The mothers are diligent in ensuring that their babies receive all their vaccinations. ${ }^{28}$ If community leaders and doctors could establish the importance of diet as something on par with the importance of vaccinations, it would contribute to changing the culture positively.

\section{Successes and further possibilities}

While the situation Bedouins are in regarding diabetes may at present seem difficult, there are some reasons to be hopeful that the situation can be improved. As public transportation continues to improve in the Negev region, it will become easier for more rural Bedouins to access clinics. There is a major clinic in the city of Rahat with a culturally competent staff including a diabetes specialist doctor and a nutritionist. Patients are able to access help in their first language and be treated by people with whom they share a cultural background. These practitioners understand the obligations and pressures commonly faced in the community and can use this knowledge to help with chronic disease management. However, the Bedouin community is still working to overcome issues such as fatalism and stigma which have a long and deep-seated history within the culture.

As mentioned before, our patient had a high position in Bedouin society and high level of education. However, even with these advantages, he still ended up suffering from kidney failure as a result of chronic diabetes and later died from diabetes complications. He did not comply with the recommended lifestyle and diet changes partly because of his fatalistic views and also because for a long time he felt physically fine. His lesson is one that shows that although many improvements have been made in terms of Bedouin diabetes management, there is still a lot of work to be carried out. To address the Bedouin diabetes problem, efforts should be geared towards increasing diabetes awareness to mitigate stigma, discussing fatalistic beliefs with patients in order to encourage adherence to treatment, and motivating the community to make healthier dietary and lifestyle choices. 


\section{Patient's perspective}

During my father's disease, his socioeconomic situation was good. He could go to the clinic, go to the dietician, and go to the experts. He was treated with insulin, but he didn't keep a diet or engage in physical activity. He was always busy with friends and people of his town. We (his family) told him to keep his diet and to engage in physical activity. However, he was non-cooperative from this point of view. He didn't consider diabetes a major threat. He was shocked when he was told he needed dialysis. He initially refused treatment for a few weeks before we convinced him with the help of his doctor. He continued dialysis while abroad, but had a heart attack. This caused a lot of shock for us. He was a father for not just the sons, but the whole family. We were astonished and sorry that he died abroad and not in Israel. We were sorry that he died. But in our society, we believe in God and see this as the will of God. We can't do anything about it. We were always afraid something bad would happen due to his non-cooperativity. Eldest son of patient.

\section{Learning points}

When encouraging patients to make lifestyle changes, interventions need to recognise cultural traditions of the patient population.

- Knowledge of chronic diseases, specifically diabetes, should be accessible to those at risk. Patients should hear this information from people they trust and it should be presented in a way that is sensitive to their beliefs.

- The Bedouin diabetes problem should be addressed by culturally competent healthcare professionals who are aware of the obstacles this population of patients faces when trying to adhere to treatment.

- Community leaders need to help spread knowledge about prevention of chronic disease.

- Doctors need to tailor care to each patient's individual situation in addition to acknowledging general cultural barriers to care.

\section{Competing interests None declared.}

\section{Patient consent Obtained.}

Provenance and peer review Not commissioned; externally peer reviewed.

\section{REFERENCES}

1 Torun B. Rural-to-urban migration and cardiovascular disease risk factors in young Guatemalan adults. Int J Epidemiol 2002;31:218-26.

2 Ebrahim S, Kinra S, Bowen L, et al. The effect of rural-to-urban migration on obesity and diabetes in India: a cross-sectional study. PLoS Med 2010;7:e1000268.
3 Williams JH, Auslander WF, de Groot M, et al. Cultural relevancy of a diabetes prevention nutrition program for African American women. Health Promot Pract 2006; 7:56-67.

4 Shaibi GQ, Konopken Y, Hoppin E, et al. Effects of a culturally grounded community-based diabetes prevention program for obese Latino adolescents. Diabetes Educ 2012:38:504-12.

5 Newman S, Cheng T, Ghahate DM, et al. Assessing knowledge and attitudes of diabetes in Zuni Indians using a culture-centered approach. PLOS ONE 2014;9: e99614.

6 Marko Kokic. Chronic diseases and health promotion. http://www.who.int/chp/en/ (accessed 24 Nov 2014).

7 Tamir 0, Peleg R, Dreiher J, et al. Cardiovascular risk factors in the Bedouin population: management and compliance. Isr Med Assoc J 2007;9:652-5.

8 Fraser D, Abu-Saad K, Abu-Shareb H. The relative importance of traditional and "modern" foods for Israeli Negev Bedouins. A population in transition. Nutr Metab Cardiovasc Dis 2001;11(4 Suppl):66-9.

9 K Abu Saad S, Weitzman Y, Abu Rabiah H, et al. Rapid lifestyle, diet and health changes among urban Bedouin Arabs in southern Israel. http://www.fao.org/docrep/ 003/Y0600M/y0600m06.htm (accessed 20 Oct 2014).

10 Yahel H. Land disputes between the Negev Bedouin and Israel. Isr Stud 2006;11:1-22.

11 ABU-SAAD I. Introduction: state rule and indigenous resistance among Al Naqab Bedouin Arabs. HAGAR Stud Cult Polity Identities 2008;8:3-24.

12 Fraser $\mathrm{D}$, Bilenko $\mathrm{N}$, Vardy $\mathrm{H}$, et al. Differences in food intake and disparity in obesity rates between adult Jews and Bedouins in southern Israel. Ethn Dis 2008;18:13-18.

13 Hansen T. Type 2 diabetes mellitus - a multifactorial disease. Ncbi.nlm.nih.gov. 2015 (cited 11 September 2015)

14 Schwartz SM, Schwartz HT, Horvath S, et al. A systematic approach to multifactorial cardiovascular disease: causal analysis. Arterioscler Thromb Vasc Biol 2012;32:2821-35.

15 Lorence $D$, Park H, Fox S. Racial disparities in health information access: resilience of the digital divide. J Med Syst 2006;30:241-9.

16 Sinai R. $66 \%$ of Negev Bedouin live below poverty line', Haaretz. 15 January 2007.

17 Friedman R. Ministers inaugurate new projects in South to help Bedouins. The Jerusalem Post 28 April 2010

18 Rabi DM, Edwards AL, Southern DA, et al. Association of socio-economic status with diabetes prevalence and utilization of diabetes care services. BMC Health Serv Res 2006;6:124-5.

19 Keeley B, Wright L, Condit CM. Functions of health fatalism: fatalistic talk as face saving, uncertainty management, stress relief and sense making. Sociol Health IIIn 2009;31:734-47

20 Heerman W, Wills M. Adapting models of chronic care to provide effective diabetes care for refugees. Clin Diabetes 2011;29:90-5.

21 Walker RJ, Smalls BL, Hernandez-Tejada MA, et al. Effect of diabetes fatalism on medication adherence and self-care behaviors in adults with diabetes. Gen Hosp Psychiatry 2012;34:598-603.

22 Shah VO, Ghahate DM, Bobelu J, et al. Identifying barriers to healthcare to reduce health disparity in Zuni Indians using focus group conducted by community health workers. Clin Trans/ Sci 2014;7:6-11.

23 Sartorius N. Stigmatized illnesses and health care. Croat Med J 2007;48:396-7.

24 Mawar N, Sahay S, Pandit A, et al. The third phase of HIV pandemic: social consequences of HIVIAIDS stigma \& discrimination \& future needs. Indian J Med 2005; 122:471-84.

25 Auer C. Gender and socio-cultural determinants of TB related stigma in Bangladesh, India, Malawi and Colombia. Int J Tuberc Lung Dis 2008;12:856-66.

26 Browne JL, Ventura A, Mosely K, et al. 'I'm not a druggie, I'm just a diabetic': a qualitative study of stigma from the perspective of adults with type 1 diabetes. BMJ Open 2014;4:e005625.

27 Swirski S, Hasson Y. Invisible Citizens: Israel Government Policy Toward the Negev Bedouin. Beer Sheva: Adva Center, Center for Bedouin Studies and Development Research Unit, Negev Center for Regional Development, Ben Gurion University of the Negev. 2006.

28 Yasur Beit Or M. Report: Bedouin children suffer poorer health. Ynetnews 2009 (cited 13 September 2015). http://www.ynetnews.com/articles/0,7340, L-3669232,00.html 
Copyright 2016 BMJ Publishing Group. All rights reserved. For permission to reuse any of this content visit http://group.bmj.com/group/rights-licensing/permissions.

BMJ Case Report Fellows may re-use this article for personal use and teaching without any further permission.

Become a Fellow of BMJ Case Reports today and you can:

- Submit as many cases as you like

- Enjoy fast sympathetic peer review and rapid publication of accepted articles

- Access all the published articles

- Re-use any of the published material for personal use and teaching without further permission

For information on Institutional Fellowships contact consortiasales@bmjgroup.com

Visit casereports.bmj.com for more articles like this and to become a Fellow 